\title{
Correction to: Selected Aspects in Searching for Health Information on the Internet Among Generation Y
}

Petra Maresova and Blanka Klimova

\author{
Correction to: \\ Chapter "Selected Aspects in Searching for Health \\ Information on the Internet Among Generation Y" \\ in: A. K. Kar et al. (Eds.): Digital Nations - Smart Cities, \\ Innovation, and Sustainability, LNCS 10595, \\ https://doi.org/10.1007/978-3-319-68557-1_20
}

The book was inadvertently published with an incorrect grant number in the acknowledgement at the end of chapter 20. "No. 15330/16/AGR" should read correctly "No. 17- 03037". Correction has been updated in chapter.

The updated version of this chapter can be found at https://doi.org/10.1007/978-3-319-68557-1_20

(C) IFIP International Federation for Information Processing 2020

Published by Springer International Publishing AG 2020. All Rights Reserved

A. K. Kar et al. (Eds.): I3E 2017, LNCS 10595, p. C1, 2020.

https://doi.org/10.1007/978-3-319-68557-1_46 